\title{
Ugandan Refugees and the Lutaya School
}

\author{
by Charles Data Male \\ Oxford, England
}

Following the fall of Idi Amin in April 1979, thousands of Ugandans have fled into exile. This is a direct result of the current struggle for leadership which has split Uganda into different political and ethnic groups. The notoriously undisciplined and ruthless government soldiers, in their ambition to root out the dissidents, have always ended up by looting, torturing and killing innocent civilians. This indiscriminate and widespread bloodshed has resulted in the mass exodus of Ugandan citizens. Abandoning all their possessions, the refugees have needed to begin a new life in their various countries of asylum.

It is estimated that more than 300,000 Ugandans now live in exile in Southern Sudan. At least as many as 150,000 live in UNHCR - assisted settlements, while the remainder decided to settle spontaneously amongst the local Sudanese population.

Although the UNHCR and the Sudan government have responded well to this massive influx of refugees, only emergency relief aid has been provided. Priority is given to food, shelter, medical aid and primary education. Despite the fact that Ugandans consider education as a basic necessity, no response to this plea has been made by the international community.

A detailed survey of the refugee settlements both spontaneous and assisted revealed that more than 15,000 refugees were "interrupted" students in various academic institutions, ranging from secondary schools, teacher-training colleges, technical colleges and university. In refuge they have no opportunity of continuing their education.

Although the Sudan government has willingly accepted to host thousands of refugees, The Sudan itself still remains one of the least developed nations of the world. There is an almost complete lack of higher educational facilities even for Sudanese citizens.

It was in 1983, after a long period of waiting without any hope, that the idea of a self-help secondary school was developed. It is hoped that the interests of both Sudanese and refugee students will be served once the Lutaya School is completed.

At the beginning the student intake will vary. Eighty percent of the available places will be allocated to refugees and 20 percent to the local Sudanese students. But, in the long run, when the refugees are able to return to Uganda, the order will be reversed, and hence 80 percent of the places will go to Sudanese while 20 percent to the Ugandans. This will also ensure that mutual understanding between the two countries is maintained. The Lutaya School will remain to express the gratitude of the Ugandan refugees to the Sudan government for their hospitality in a time of need.

From the time of its conception, all the work carried out in connection with the school has been on a voluntary basis. Refugee students, teachers, and the local people work hand-in-hand. There is abundant labour from the refugees. To date, a block of buildings divided into three apartments has been completed. Another block, designed to provide an office and more classrooms is now under construction.

Although the project was meant to be entirely the work of refugees, it must be understood that there are limitations. There is a shortage of building mater- ials: roofing material, cement, and other items cannot be obtained locally. Moreover, money is required to purchase them.

However, this project has been supported by the Third World First organization of Oxford University, World University Service (UK), and the Jesuit Refugee Service. Third World First has raised $£ 2,320$ so far and has also been involved in the collection of books and other scholastic materials that will help the refugees generally. WUS has responded by shipping the books to Yei and is also trying to develop libraries in the various refugee camps. Added to this, the Jesuit Refugee Service has offered to send an administrator in addition to Father Victor Mathias (currently UNHCR's Field Office Education Officer) who is working with the refugees.

It is worth mentioning that links between the Ugandan refugee community in southern Sudan and the international community (especially Britain) have been progressing well over the past two years. Last year a group of students from Third World First, Oxford University, visited the refugees. When they returned they were able to inform the British people of the plight of the refugees. This year a repeat visit is taking place. Instead of two students, seven are going to spend two months with the refugees.

Such visits help to create nontangible links and cooperation amongst people here and the oppressed peoples of the world. It also fills the refugees with new hope, and a feeling of belonging to the rest of humanity. Once we view refugees as part of humankind, doubtless they will once again become highly motivated. 